\title{
COMPORTAMENTO DE CINCO GENÓTIPOS DE COQUEIRO (Cocos nucifera L.) NA FASE DE GERMINAÇÃO E DE CRESCIMENTO DE MUDAS, SOB DIFERENTES SISTEMAS DE PRODUÇÃO ${ }^{1}$
}

\author{
WALDIR SEBASTIÃO DE FARIA², HILTON NEY GAÍVA, WALTER E. PEREIRA ${ }^{4}$
}

\begin{abstract}
RESUMO - Com o objetivo de avaliar o comportamento de cinco genótipos de anões e híbridos de coqueiro: anão-verde de Jiqui (AVeJ), anão-vermelho de Gramame (AVG), anão-amarelo da Malásia (AAM), híbrido de anão-vermelho de Gramame x gigante-Brasilda-praia-do-Forte (AVG x GBrPF) e o híbrido de anão-amarelo de Gramame x gigante do oeste Africano (AAG x GOA), na fase de germinação de sementes e de crescimento de mudas, em diferentes sistemas de produção, foi instalado um experimento em $1^{\circ}$-08-1998, na Fazenda Experimental da Faculdade de Agronomia e Medicina Veterinária da Universidade Federal de Mato Grosso, localizada no município de Santo Antônio do Leverger. Avaliou-se o comportamento dos cinco genótipos quanto à germinação de sementes e ao crescimento das mudas provindas de sementes colocadas nas posições horizontal e vertical, e mantidas a $50 \%$ de sombra ou a pleno sol. A combinação fatorial desses fatores resultou em 20 tratamentos, que foram dispostos no delineamento inteiramente casualizado, com três repetições. As características avaliadas foram as seguintes: germinação acumulada, percentagem de germinação, percentagem de mudas aptas a serem transplantadas para o campo, altura das mudas, número de folhas, circunferência do coleto, peso da muda e peso da parte aérea. O híbrido (AAG x GOA) e o AVG apresentaram, respectivamente, maiores e menores valores para as características: percentagem de germinação, percentagem de mudas aptas a irem para o viveiro, número de folhas, circunferência do coleto e de altura aos 30; 60 e 90 dias após o plantio no viveiro. As mudas de maiores pesos corresponderam ao híbrido (AVG x GBrPF) e as de menores pesos, ao AAM. O híbrido AVG x GBrPF produziu mudas com parte aérea mais pesada e o AVG, as mais leves. As mudas obtidas a partir de sementes sob sombra de $50 \%$ apresentaram maiores alturas e pesos. As sementes colocadas na posição horizontal produziram mudas mais altas aos 30 e 60 dias de viveiro, e maior número de folhas.
\end{abstract}

Termos para indexação: coco, posição de semeadura, sombreamento

\section{BEHAVIOR OF FIVE GENOTYPES OF COCONUT TREE (Cocos nucifera L.) IN THE PHASE OF GERMINATION AND SEEDLING GROWTH, UNDER DIFFERENT SYSTEMS OF PRODUCTION}

\begin{abstract}
With the objective to evaluate the performance of five genotypes of dwarf and hybrids of coconut tree: dwarf green of Jiqui (AVeJ), red dwarf of Gramame (AVG), dwarf yellow of Malaysia (AAM), hybrid of red dwarf Gramame $x$ giant Brazil of Forte beach (AVG x GBrPF) and the hybrid of dwarf yellow of Gramame $x$ giant of the African west (AAG x GOA), in the germination and growth stage, in different production systems, an experiment was carried out in August of 1998, in the Experimental Station of the Faculdade de Agronomia e Medicina Veterinária of the Universidade Federal of Mato Grosso, located in Santo Antônio de Leverger. It was evaluated the performance of five genotypes of coconut tree in the germination and growth stage of seedlings originated from seeds placed in the horizontal and vertical positions, and kept at $50 \%$ of shade or full sun. Those factors were combined factorially, resulting in 20 treatments, which were arranged in the completely randomized design. The evaluated characteristics were: accumulated germination, percentage of germination, percentage of seedling capable of being transplanted for the field, seedling height, number of leaves, circumference of the girth, weight of the seedling and weight of the aerial part. The hybrid (AAG x GOA) and the AVG presented, respectively, larger and smaller values for the characteristics: germination percentage, percentage of seedling capable of being transplanted for the field, number of leaves, circumference of the girth and of the seedling heights to the 30, 60 and 90 days of nursery. The seedlings of larger weights corresponded to the hybrid (AVG x GBrPF), and the one of smaller weights, to the AAM. The hybrid AVG $x$ GBrPF produced seedlings that presented heavier aerial part and AVG the lightest. The seedlings produced from the seeds under shade of 50\% presented larger heights and weights. The seeds germinated in the horizontal position produced seedlings higher to the 30 and 60 days of nursery, and larger number of leaves.
\end{abstract}

Index terms: coconut, sowing position, shading

\footnotetext{
1 (Trabalho 184/2001). Recebido: 19/11/2001. Aceito para publicação: 02/05/2002. Parte da tese do primeiro autor apresentada à Universidade Federal de Mato Grosso (UFMT), para a obtenção do grau de Mestre em Agricultura Tropical.

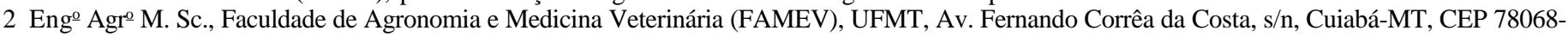
900. Tel. 0xx-65-615-8601

3 Eng ${ }^{\circ}$ Agr $^{\circ}$ D. Sc., Professor Adjunto - FAMEV/UFMT.

4 Eng ${ }^{\mathrm{o}}$ Agr $^{\mathrm{o}}$ D. Sc., Bolsista DCR do CNPq - FAMEV/UFMT. Email: wep69@ bol.com.br
} 


\section{INTRODUÇÃO}

No Estado de Mato Grosso, a cocoicultura vem expandindo-se consideravelmente (Gaiva \& Santos, 1999), tendo como principal empecilho técnico, para maior expansão, as dificuldades em se obter mudas de genótipos produtivos e de variedades comprovadamente adaptadas à região.

O sucesso da implantação de um coqueiral está na origem genética da semente, na formação, no vigor e na sanidade das mudas, que são indispensáveis para obtenção de plantas que apresentem alta produtividade (Fontes et al., 1998).

Segundo Taffin \& Ouvrier (1985), citados por Fontes et al. (1998), as sementes, quando colhidas completamente secas (11 a 12 meses), iniciam a germinação entre 40 e 60 dias após a semeadura, no caso de variedades anãs; 70 a 90 dias para os híbridos e 100 a 150 dias para a variedade Gigante.

Wuidart (1979), citado por Passos (1998), afirma que as mudas podem ser produzidas em sacos plásticos, com seis a oito meses de enviveiramento, devendo apresentar 18 a $20 \mathrm{~cm}$ de circunferência do coleto, com sete a oito folhas vivas e 1,1 a 1,2 $\mathrm{m}$ de altura com folíolos diferenciados.

Recomenda-se, para o plantio, a utilização de mudas com 1,0 m de altura, 15 a $18 \mathrm{~cm}$ de circunferência do coleto e cinco a sete folhas vivas (Embrapa, 1986)

Atualmente, tem-se observado a preferência pela utilização de mudas mais jovens, com três a quatro folhas, por apresentarem menor área foliar e maior teor de reserva no endosperma, com quatro meses de enviveiramento (Passos, 1998).

Passos (1998) obteve o percentual de germinação de $89,6 \%$ aos 126 dias, utilizando o ecotipo gigante-do-Brasil de Itaporanga, quando estudava três fases de maturação dos frutos destinados para sementes, no Campo Experimental de Itaporanga-SE.

Fontes \& Leal (1998), no Campo Experimental de Itaporanga/SE, quando estudavam o híbrido (anão-verde de Jiqui x gigante-do-Brasil), obtiveram germinação média de $87,9 \%$; até o quarto mês, e aos 163 dias após a semeadura, a circunferência do coleto foi de $7,15 \mathrm{~cm}$.

Estudando efeito do entalhe da semente sobre a germinação do coqueiro-gigante-do-Brasil, Fontes \& Leal (1994) obtiveram $68,8 \%$ das sementes germinadas com entalhe e $74,7 \%$ naquelas não entalhadas. Com relação à intensidade de iluminação, houve diferenças significativas, com germinação de $74,4 \%$ à sombra e $69,1 \%$ a pleno sol.

Passos et al. (1998), avaliando o comportamento germinativo da semente e o crescimento da plântula do coqueiro-anão-verde, na estação experimental de Jales-SP, obtiveram $36,7 \%$ de sementes germinadas, aos 194 dias, quando houve temperaturas inferiores a $15^{\circ} \mathrm{C}$, sem ocorrência de geadas.

A opção pela distribuição das sementes na posição vertical tem sido bastante utilizada entre alguns produtores, não tendo sido observada nenhuma diferença com relação ao índice final de germinação das sementes. Tem-se verificado, no entanto, que esse sistema facilita o transporte, reduz o problema de quebra do coleto, dispensa o entalhe e permite maior número de sementes por área (Fontes, 1998).

Wuidart \& Nucé de Lamothe (1981), citados por Fontes et al. (1998), comparando as posições horizontal e vertical de distribuição de sementes, concluíram que, embora tenham apre- sentado retardamento inicial, as sementes dispostas verticalmente apresentaram pequena vantagem na germinação final. Verificaram, ainda, que as variações observadas no índice de germinação, comparando-se variedades diferentes, podem ser atribuídas ao conteúdo do endosperma líquido e a distância que separa este endosperma do embrião.

O presente trabalho teve o objetivo de avaliar o comportamento de diferentes genótipos de anões e híbridos do coqueiro, na fase de germinação e desenvolvimento de mudas, em diferentes sistemas de produção.

\section{MATERIAL E MÉTODOS}

Este experimento foi instalado no dia $1^{\circ}-08-98$ na Fazenda Experimental da Faculdade de Agronomia e Medicina Veterinária da Universidade Federal de Mato Grosso, localizada no município de Santo Antônio do Leverger, a uma altitude de $165 \mathrm{~m}$ e latitude de $15^{\circ} 47^{\prime} \mathrm{S}$ e longitude $56^{\circ} 04^{\prime} \mathrm{W}$. A temperatura média observada no período foi de $26,7^{\circ} \mathrm{C}$; o maior valor para a temperatura máxima ocorreu nos meses de outubro e fevereiro $\left(34,3^{\circ} \mathrm{C}\right)$, e a menor mínima, com $15,2^{\circ} \mathrm{C}$, em agosto.

Avaliaram-se os efeitos de cinco genótipos: anão-verde de Jiqui (AVeJ), anão-vermelho-de-Gramame (AVG), anão-amarelo da Malásia (AAM), híbrido anão-vermelho Gramame x gigante-Brasil-da-praia-do-Forte (AVG x GBrPF) e o híbrido anão-amarelo de Gramame x gigante do oeste Africano (AAG x GOA), em duas posições de semeadura: horizontal com entalhe, e vertical e duas condições de iluminação: sombreada $(50 \%)$ e a pleno sol. Esses fatores foram combinados fatorialmente, resultando em 20 tratamentos que foram distribuídos no delineamento inteiramente casualizado, com três repetições, sendo os dados submetidos à análise de variância e ao teste de Tukey.

Os germinadouros constaram de canteiros preparados com 1,2 m de largura, sendo dois cobertos com sombrite (50\%) e dois a pleno sol. Para cada metro quadrado de canteiro, foram colocadas 25 sementes, distribuídas lado a lado, e cobertas com terra vegetal até aproximadamente dois terços de suas alturas. A avaliação da percentagem de germinação foi encerrada aos 120 dias após a instalação do experimento.

Posteriormente, efetuou-se a seleção das mudas, descartando-se as anormais (albinas, bifurcadas, etc.). A seguir, realizou-se transplante para sacos plásticos de polietileno preto, com 0,2 mm de espessura e dimensões $0,40 \times 0,40 \mathrm{~m}$, nos quais se utilizou substrato: mistura de $2 / 3$ de terra de superfície devidamente peneirada, $1 / 3$ de palha de arroz carbonizada e enriquecida com $250 \mathrm{~g}$ de superfosfato simples.

As sacolas foram enchidas até a metade com o substrato e as mudas plantadas com as raízes aparadas a $1 \mathrm{~cm}$ de comprimento, completando o volume da sacola com o substrato, trabalho esse realizado à sombra para se evitar estresse nas mudas.

No viveiro, obedeceu-se ao espaçamento de 0,80 x 0,80 x 0,80 m em triângulo eqüilátero, permanecendo 8 meses a pleno sol. O viveiro foi mantido livre de plantas daninhas e recebeu adubações foliares e tratos fitossanitários recomendados para a cultura (EMBRAPA, 1986). Foram realizadas regas de 6 a 7 litros de água por metro quadrado, tanto na fase de germinadouro, quanto na de viveiro.

Avaliou-se a percentagem de germinação, obtida atra- 
vés da relação: número de sementes colocadas para germinar pelo número de sementes germinadas, durante o período de avaliação (quatro meses); o percentual de mudas selecionadas aptas a serem plantadas no campo; a altura das mudas aos 30; 60 e 90 dias após a semeadura, utilizando-se de régua graduada de 2,5 metros, colocando-a sobre a noz e medindo-se até a extremidade mais alta; o número de folhas; o peso da muda e o peso da parte aérea, sendo estes três últimos obtidos no terceiro mês de viveiro, ou seja, no sétimo mês após a semeadura.

\section{RESULTADOS E DISCUSSÃO}

Na percentagem de germinação, foi verificado efeito significativo dos genótipos avaliados. Os híbridos AVG x GBrPF e AAG x GOA não apresentaram diferenças entre si, e entre os anões AVeJ e AAM, variando de 75,0 a 88,1\%. Já o AVG, com $60 \%$, apresentou o menor valor, como ilustra a Figura 1.

Comparando aos resultados obtidos por Passos (1998), que obteve, aos 126 dias após semeadura, valores de $89,6 \%$ na germinação de sementes da cultivar gigante-do-Brasil de Itaporanga, verificando-se valores próximos aos obtidos neste experimento, com exceção da AVG (Figura 1). Fontes \& Leal (1998) obtiveram média de $87,9 \%$ de germinação para o híbrido anãoverde de Jiqui x gigante-do-Brasil. Esse resultado está próximo aos obtidos com os genótipos avaliados neste experimento.

Fontes \& Leal (1994), estudando o efeito do entalhe da semente, sobre germinação do coqueiro-gigante-do-Brasil, não detectaram efeito significativo, de forma semelhante aos resultados obtidos neste experimento.

Quando as mudas foram mantidas à sombra, a percentagem de mudas aptas para o plantio variou de 70 a $91 \%$, nos genótipos AVeJ, AAM, AVG x GBrPFe AVG x GOA, os quais não diferiram entre si. Já o AVG apresentou o menor valor de germinação de mudas $(50 \%)$, sendo significativamente menor que os outros mencionados (Figura 1). Quando as mudas foram mantidas ao sol, não foi verificada diferença significativa entre os genótipos avaliados.

Verificou-se diferença significativa entre as mudas mantidas à sombra e ao sol somente para o AVeJ, onde as que cresceram à sombra, apresentaram maiores valores de percentagem de mudas aptas para o transplantio (Figura 1).

A percentagem de mudas aptas para o plantio, obtida com os genótipos avaliados, permite aos produtores estimarem a percentagem de mudas que terá a sua disposição para o plantio no campo.

Os genótipos AAG x GOA, AVG x GBrPF e AVeJ apresentaram maiores alturas aos 30; 60 e 90 dias, sendo que, aos 90 dias, apresentaram 1,61; 1,60 e 1,35 m de altura, respectivamente (Tabela 1). O anão-vermelho de Gramame com 1,09 m apresentou a menor altura, aos 90 dias após transplantio, diferindo significativamente dos citados acima.

Com relação ao efeito de condição de crescimento, verificou-se maior altura significativa das plantas quando cresceram com 50\% de sombra, em todas as épocas avaliadas (Tabela 2 ). Esses resultados podem estar relacionados aos efeitos inibitórios da elevada luminosidade sobre a fotossíntese, de acordo com o mencionado por Osmond et al. (1997).

Observou-se que as mudas provenientes de sementes colocadas na posição horizontal apresentaram maiores alturas (Tabela 3).

Wuidart (1979), citado por Passos (1998), menciona que as mudas devem apresentar 1,1 a 1,2 m de altura com folíolos diferenciados, e a Embrapa (1986) recomenda a utilização de mudas com 1,0 m de altura, valores menores que os encontrados nesta pesquisa.

Os híbridos AAG x GOA e AVG x GBrPF e o AVeJ apresentaram a maior média de número de folhas, já o AVG apresentou o menor número de folhas (Figura 1). Como o processo fotossintético ocorre principalmente nas folhas, os genótipos que apresentaram maior número de folhas, tiveram maior disponibilidade de fotoassimilados e, conseqüentemente, maior crescimento, como pode ser verificado na altura das mudas (Tabela 1)

Considerando o efeito das posições de semeadura, verificou-se que as mudas provenientes de sementes colocadas na posição horizontal apresentaram maior número de folhas, quando comparadas com as mudas provenientes de sementes na posição vertical (Tabela 3).

Passos (1998) recomenda, para plantio no campo, mudas com três a quatro folhas e com quatro meses de enviveiramento, valores semelhantes aos encontrados nesta pesquisa. O número de folhas obtido neste experimento foi inferior ao recomendado pela Embrapa (1986), que é de utilizar mudas com cinco a sete folhas vivas. Apesar deste menor número de folhas, as mudas apresentavam-se com maior crescimento em altura, como citado anteriormente.

De acordo com a Figura 1, verifica-se que os genótipos

TABELA 1 - Médias das altura das plantas, aos 30 (A30), 60 (A60) e 90 dias (A90) após o transplantio, nos genótipos anão verde-deJiqui (AVeJ), anão-vermelho-de-Gramame (AVG), anão-amarelo-da-Malásia (AAM), anão-vermelho Gramame x giganteBrasil-da-praia-do-Forte (AVG x GBrPF) e anão-amarelo de Gramame x gigante do oeste Africano (AAG x GOA).

\begin{tabular}{|c|c|c|c|}
\hline \multirow[t]{2}{*}{ Genótipo } & \multicolumn{3}{|c|}{ Altura (m) } \\
\hline & A 30 & A 60 & A 90 \\
\hline$A A G \times G O A$ & $1,36 \mathrm{~A}$ & $1,50 \mathrm{~A}$ & $1,61 \mathrm{~A}$ \\
\hline A VG $x$ GBrPF & $1,34 \mathrm{~A}$ & $1,49 \mathrm{~A}$ & $1,60 \mathrm{~A}$ \\
\hline A V eJ & $1,17 \mathrm{~B}$ & $1,29 \mathrm{~A}$ & $1,35 \mathrm{~A}$ \\
\hline A A M & $1,06 \mathrm{~B} \mathrm{C}$ & $1,14 \mathrm{BC}$ & $1,23 \mathrm{BC}$ \\
\hline A V G & $0,90 \mathrm{C}$ & $1,05 \mathrm{C}$ & $1,08 \mathrm{C}$ \\
\hline
\end{tabular}

Médias seguidas por uma mesma letra na vertical não diferem significativamente entre si, a 5\% de probabilidade, pelo teste de Tukey.

Rev. Bras. Frutic., Jaboticabal - SP, v. 24, n. 2, p. 458-462, agosto 2002 
TABELA 2 - Média de altura das plantas, aos 30 (A30), 60 (A60) e 90 dias (A90) após a semeadura, nas condições de sombra a 50\% e sol

\begin{tabular}{cccc}
\hline Condição & Altura (m) \\
\hline & A 30 & A60 & A 90 \\
Sombra & $1,21 \mathrm{~A}$ & $1,36 \mathrm{~A}$ & $1,44 \mathrm{~A}$ \\
Sol & $1,13 \mathrm{~B}$ & $1,24 \mathrm{~B}$ & $1,32 \mathrm{~B}$ \\
\hline
\end{tabular}

Médias seguidas por uma mesma letra não diferem significativamente entre si, a 5\% de probabilidade, pelo teste de Tukey.

TABELA 3 - Média da altura, do número de folhas e do peso da parte aérea das mudas em função das posições horizontal e vertical de semeadura

\begin{tabular}{cccc}
\hline Posição & Altura (m) & Número de folhas (Un.) & Peso da parte aérea (kg) \\
& & & \\
\hline Horizontal & $1,35 \mathrm{~A}$ & $3,54 \mathrm{~A}$ & $0,531 \mathrm{~A}$ \\
Vertical & $1,22 \mathrm{~B}$ & $3,33 \mathrm{~B}$ & $0,403 \mathrm{~B}$ \\
\hline
\end{tabular}

Médias seguidas por uma mesma letra não diferem significativamente entre si, a 5\% de probabilidade, pelo teste de Tukey.
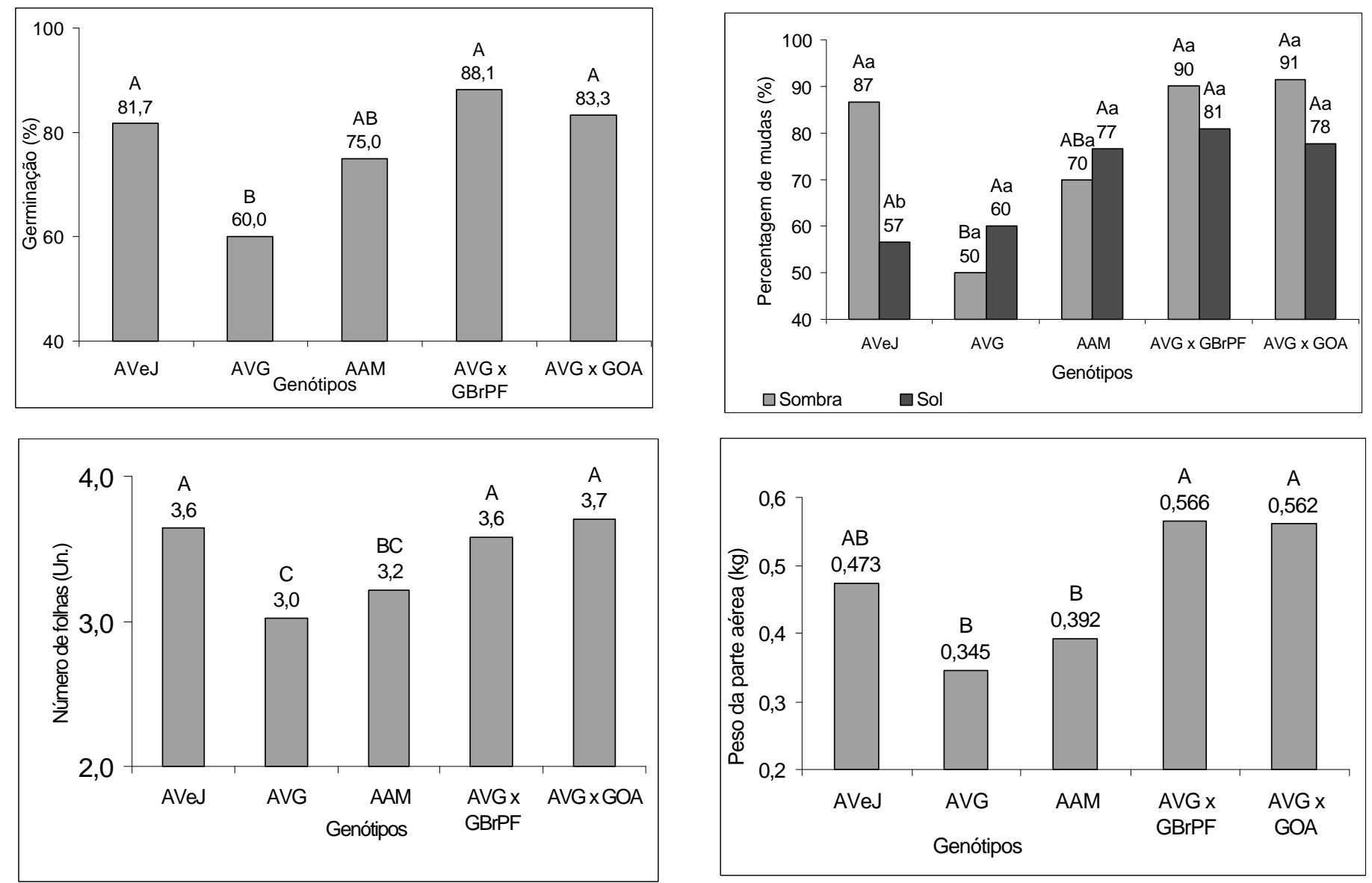

Médias seguidas da mesma letra maiúscula, utilizadas para comparar genótipos dentro de cada condição, e da mesma letra minúscula, utilizadas para comparar as condições dentro de cada genótipo, não diferem entre si, a 5\% de probabilidade, pelo teste de Tukey.

FIGURA 1 - Percentagem de germinação, percentagem de mudas aptas para serem transplantadas ao campo, número de folhas e peso da parte aérea de cinco genótipos de coqueiro: anão verde de Jiqui (AVeJ), anão-vermelho-de-Gramame (AVG), anãoamarelo da Malásia (AAM), anão-vermelho Gramame x gigante-Brasil-da-praia-do-Forte (AVG x GBrPF) e anão-amarelo de Gramame x gigante do oeste Africano (AAG x GOA). 
AVG x GBrPF, AAG x GOA e AVeJ apresentaram maior peso da parte aérea. Já os menores valores foram obtidos nos genótipos AVG, AAM, que não diferiram do AVeJ.

Avaliando as posições de semeadura, o maior peso da parte aérea foi obtido nas mudas provenientes de sementes colocadas na posição horizontal (Tabela 3).

Fontes \& Leal (1998) obtiveram peso da parte aérea das mudas menor $(0,246 \mathrm{~kg})$ que os encontrados nesta pesquisa para o híbrido anão-verde de Jiqui x gigante-do-Brasil, no Campo Experimental de Itaporanga, aos 230 dias.

As mudas que apresentam maior peso da parte aérea têm maior possibilidade de apresentarem área foliar maior, facilitando o estabelecimento inicial das mudas no campo.

\section{CONCLUSÕES}

1. Os híbridos apresentaram melhor desempenho quanto à porcentagem de germinação das sementes e vigor das mudas aptas ao plantio avaliado pela altura, número de folhas e peso.

2. O anão-verde de Jiqui apresentou desempenho comparável aos híbridos e o anão-vermelho de Gramame o menor desempenho.

3. A produção de mudas sob condições de sombreamento proporcionou a obtenção de plantas com maior vigor, assim como, as germinadas na posição horizontal.

\section{REFERÊNCIAS BIBLIOGRÁFICAS}

EMBRAPA. Produção de mudas de coqueiro. Aracaju: Empresa Brasileira de Pesquisa Agropecuária, 1986. 16p. (Circular técnica, 2).

FONTES, H. R.; CINTRA, F. L. D.; CARVALHOFILHO, O. M. C. Implantação e manejo da cultura do coqueiro. In: FERREIRA, J. M. S.; WARWICK, D. R. N.; SIQUEIRA, L. A.A (Ed.). A cultura do coqueiro no Brasil. Aracaju: Empresa Brasileira de Pesquisa Agropecuária, 1998, p. 99 - 128.

FONTES, H. R.; LEAL, M. L. da S. Efeito da irrigação, cobertura morta e entalhe da semente, sobre germinação do coqueiro gigante-do-Brasil. Aracaju: Empresa Brasileira de Pesquisa Agropecuária, 1994. 7p. (Comunicado técnico, 5).

FONTES, H. R.; LEAL, M. L. da S.Produção de mudas de coqueiros (Cocos nucifera L.) pelo sistema alternativo. Aracaju: Empresa Brasileira de Pesquisa Agropecuária, 1998. 5p. (Comunicado técnico, 22).

FONTES, H. R.; Influência da posição e entalhe da semente sobre a germinação acumulada e qualidade da muda de coqueiros (Cocos nucifera L.). Aracaju: Empresa Brasileira de Pesquisa Agropecuária, 1998. 6p. (Comunicado técnico, 23).

GAIVA, H. N.; SANTOS, A. M. A cultura do coqueiro no Mato Grosso. In: SÃO JOSÉ, A. R.; SOUZA, I. V. B.; MOURA, J. I. L.; REBOUÇAS, T. N. H.(Ed.). Coco: produção e mercado. Vitória da Conquista: DFZ/UESP, 1999. p.182-195.

OSMOND, B. et al. Too many photons: photorespiration, photoinibition and photooxidation. Trends in Plant Science, Amsterdam, v. 2, n. 4, p. 19-121, 1997.

PASSOS, E. E. M. Influência da maturação do fruto na germinação da semente de coco. Aracaju: Empresa Brasileira de Pesquisa Agropecuária, 1998. 3p. (Comunicado técnico, 27).

PASSOS, E. E. M.; CONCEIÇÃO, M.A. F.; MAIA, J. D. G. Germinação da semente e desenvolvimento da plântula de coqueiroanão-verde no noroeste de São Paulo. Aracaju: Empresa Brasileira de Pesquisa Agropecuária, 1998. 5p. (Comunicado técnico, 12). 